natives got neither vegetables nor meat. Here I may simply refer to the case of the diet question of convicts of Iudian prisons, which has recently excited considerable controversy both in the lay and in the medical press and in Parliament. I in common with everybody else who has read aud studied his report, am entirely in aceord with Dr. Cunniugham when he writes ("Seventeenth Aunual Report of the Sanitiry Commissioner with the Government of India," 1880) that there are other causes at work in prisinns to account for ill-health, including scurvy, beside the "Conference" diet, to which all the blame appears to be attached hy most reviewers of that publication. The excelient scientific report by Dr. Lewis ought to satisfy the critical analyst. In the case of the troops in Afghanistin, I believe the scorbutic taint existed largely in both Europeans and natives, though it was more matked in the latrer.

2. Ennui, with absence of surroundings calculated to stimulate and cheer the mind, and the existence of almost everything likely to depress it to a degree, such as was the case there; prolonged stay in the same uninteresting places, with the same identical, forsooth dismal, scenes.

3. Harassing and arduous duties, or absolute idleness, under the above-mentioned circumstances.

The monograph by Dr. Robert Mosdie, late of the Indian Medical Service, now practising at Stirling, is a most interesting contribution on the subject of scurvy, the outcome of observations by an accomplished physician who in the late Afghan war availed himself of the opportunities which presented themselves. To it I would beg to invite the attention of my professional brethren.

I am, Sir, yours truly,

Ahmedabad, July 11th, 1882. JOHN C. LUCAS.

\section{SULPHIDE OF CALCIUM IN CANCER.}

\section{To the Editor of THE LANCET.}

SIR, -The distressing and fatal nature of cancer in its various forms prevents my offering to the profession any apology for bringing before their notice the sulphide of calcium as a therapeutic agent in the treatment of the disease. In doing this, I wish to state that I do not claim for the remedy any completely curative power without operation; still, in several cases which have been treated by me without operation, the drug certainly seems to have had more effect than any other with which $I$ am acquainted in retarding the growth of the malady.

I was first induced to try sulphide of calcium about three years ago, after having read Dr. Ringer's article on that remedy in his Handbook of Therapeutics.

The first case in which I tried the sulpkide was that of E S - , aged thirty-four years, the wife of an agricultural labourer. She had suffered from cancer of the breast for about twelve months, and persistently refused to undergo an operation until she saw death from the disease was inevitable. I undertook the operation at her own request, with the view of prolonging her life, and in favour of her infant child, but without any hope of her ultimate recovery. When admitted into our cottage hospital she was much emaciated, and the cancerous cachexia was decidedly marked. Nearly the entire breast was affected, the nipple retracted, and the skin adherent. The growth was very hard and nodular; superficial veins large and dark; glands in the axilla enlarged; and there appeared to be nothing wanting to complete a correct diagnosis of the disease, which was confirmed by four medical men. The entire breast was removed, under chloroform, the wound treated in the usual manner, and the patient made a rapid recovery. She gained flesh in a remarkable manner, and went out of the hospital quite well and strong, and remains so to this day. She has, since the operation, had another child. She was in hospital two months. I commenced to give her one grain of the sulphide daily on admission. In a few days this was increased to three grains a day, and continued for three months.

The second case was that of J. F___, aged thirty-five, unmarried. She had for some months a hard scirrhous lump under the right nipple, which was very painful, and greatly increased whilst she was nursing a brother through a severe attack of enteric fever. I will not enter into the details of the case further than to state that my diagnosis was confirmed by two or three medical men, one of whom is a visiting surgeon of the Lincoln County Hospital, and he was present at the operation. This patient was kept under the sulphide of calcium treatment some months, and is quite well, withont a trace of the dise $t s, b+$ ing left.

The third case is that of $\mathrm{E} N$ - aged thirty-five years, a widow, a laundress, and mother of seven children. She had suffer $d$ for some months from a hard, painful, and increasing lump in the right breast; had been losing flesh for twelve months, and was much exhau ted. Her mother's sister had died from cancer. I amputared the breast at the cottage hospital under chloroform. The patient bled very profusely, and was taken from the table very much bldnched. Her recovery was remarkable; she gained flesh and strength very quickly, and in a manner which surprised me, and she has since married, and expresses herself quite well. She left the hospital in December last. She was kept for four months under the sulphide treatment. I may say that the diagnosis of this case was confirmed by three other qualified men.

I publish these cases in the hope that the remedy which certainly appears to have been of service in my hands may be of still greater benefit in the hands of others. I am, Sir, yours truly,

EDwir W BARTon, M.D.Brus., L.R.C.P.Lond Market Rasen, Aug. 21st, 1882

\section{FAT EMBOLISM IN DIABETES To the Editor of THE LANCET.}

SIR,-May I crave space to correct your brief notice of my remarks in the discussion on diabetes in the Pathological Section at Worcester? You report me to have said that I had found very few fat embola in my cases of diabetic coma. What I did say was that I had found no true fat embola in a case of diabetic coma in which the blood was extremely fatty ; and I referred to the paper by Dr. Barling and myself in the July number of the Journal of Anatomy and Phy. siology, in which we showed that the fat merely collected in globules of less size than the lumen of the ve-sels, and lay emberded in the post-mortem thrombi. I also drew attention to the frequency of fat embola in fractures, and to the absence of symptoms in these cases, unless the embola were extremely numerous. I am, Sir, yours faithfully, Birmingham, Aug. 19th, 1882. : ROBERT SAUNDBY, M.D.

\section{COTTAGE HOSPITALS.}

\section{To the Editor of THE LANCET.}

SIR,-You suggested in an article some time ago that it was desirable that each Cottage Hospital committee should contribute in its corporate capacity a small sum, in no case exceeding $£ 5$, to the Napper Testimonial Fund. Some of the hospitals appear to take up this suggestion warmly, but I regret to say that as a matter of fact not a single cottage hospital in its corporate capacity, of the whole of the three hundred and twenty at present existing in this country, has sent one penny to the Napper Fund. I have taken a con. siderable interest in cottage hospitals, and have done my best to promote their efficiency and success. For this reason, perhaps, I not unnaturally feel zealous for the honour of these useful institutions, and I desire to ask the members of the medical staff of cottage hospitals throughout the country to bring the subject of the Napper Testimonial before an early meeting of their committee with the view of ascertaining if any, and what, contribution shall be given to it. Personally it is not the amount which I shall value, and a subscription of even five shillings would be regarded by me with satisfaction as evidence that great public services rendered by an exceptionally ahle and good man were not forgotten by those who have most benefited by them. I urge the medical men in question, and I earnestly beg of all of them with whom I am personally acquainted to remove this slur from the escutcheon of cottage hospitals by sbowing at once that in the case of those which are best managed, at any rate, gratitude is not a lively expectation of favours to come. Let edch member of the medical profession resident in the country ask himself what he owes to $\mathrm{Mr}$. Napper, whose foresight originated, and whose invariable readiuess to give substantial help and information secured the success, of the majority at any rate, of the cottage hospitals which are scattered throughout the country to-day. It is, of course, a 